\title{
Effect of counselling on the family function of intimate partner violence victims attending antenatal clinic in a tertiary hospital in North Central Nigeria
}

\author{
${ }^{a}$ Department of Family Medicine, University of Abuja Teaching Hospital, Gwagwalada, Nigeria \\ ${ }^{b}$ Department of Family Medicine, National Hospital, Abuja, FCT, Nigeria \\ *Corresponding author, email: blessingaj@yahoo.com
}

BO Akor $^{a *}$, LA Moses ${ }^{b}$, ND Baamlong ${ }^{a}$, LL Shedul ${ }^{a}$, AS Haruna ${ }^{a}$, JM Abu ${ }^{a}$, OU Chira ${ }^{a}$, NR Ripiye ${ }^{a}$ and RA Abdulkareem ${ }^{a}$

Background and aim: Intimate partner violence (IPV) is a global problem. Family dysfunction is an integral characteristic of IPV homes. However, not much has been done regarding restoration of these families. The aim of this study was to explore the effect of counselling on the family function of pregnant IPV victims, with a view to recommending an appropriate interventional strategy.

Methods: The study was a single-blinded randomised controlled trial of pregnant IPV victims. The Abuse Assessment Scale (AAS) was used to recruit 72 IPV victims who were randomised into the control and intervention arms of 36 each. Their sociodemographic data were collected. The family function of the victims was assessed using the SCORE-15 index of family function at the beginning the study. The intervention arm had three sessions of counselling lasting one to two hours fortnightly using the SOS DoC protocol. The family function was repeated post intervention. Data were analysed using SPSS version 20 and a $p$-value of $<0.05$ was considered significant.

Results: The majority (82\%) of the IPV victims had dysfunctional families. Baseline mean family function score across the groups showed no statistically significant difference. Post intervention, the mean family function score improved from $2.92 \pm 0.92$ to $2.16 \pm 0.63$ and this change was statistically significant $(p<0.0001)$. In the control arm, the change from $2.48 \pm 0.73$ to $2.29 \pm$ 0.82 was not statistically significant $(p=0.116)$.

Conclusion: Short-term counselling significantly improved the family function of IPV victims.

Keywords: counselling, family, function/dysfunction, IPV (intimate partner violence), SOS Doc (S-offer support and assess safety, O-discuss options, S-validate patient's strengths, Do-document observations, assessment, and plans, C-offer continuity), SCORE-15 (Systemic Clinical Outcome and Routine Evaluation 15)

\section{Introduction}

Intimate partner violence (IPV) is a destroyer of the family unit. This is clearly evident from the menace the 'worm' creates in every aspect of the family. ${ }^{1}$ The perpetrator, whether male or female, is usually unapproachable and beyond control by the victim. ${ }^{2}$ The children are not unaffected. It has been shown that children from IPV families have an IQ up to eight points lower when compared with their counterparts. ${ }^{3}$ Behavioural challenges also characterise children from violent homes ${ }^{4,5}$ as they are seen to exhibit different vices ranging from substance abuse to bullying and stealing, amongst others. Individuals from violent homes are also prone to hospital visits on account of accidental injuries from physical trauma or other health challenges. ${ }^{6}$ Hence family dysfunction thrives in a family with intimate partner violence.

According to Nugent, ${ }^{7}$ a dysfunctional family is one that shows impaired communication and relationships where members are unable to get close. It is a family whose normal healthy functioning is impeded through negative behaviour such as abuse, apathy, neglect or lack of emotional support, which constitute the various forms of IPV. ${ }^{8}$ In a dysfunctional family, the relationship between the parent and child is tense and unnatural; parents constantly neglect or abuse the child and the other family members accommodate such behaviour. In some cases, children end up with low self-esteem and grow up with the belief that such behaviour is normal. ${ }^{5}$ A dysfunctional family has several challenges that go on in a vicious cycle. Hence there is a great need to try to prevent or stop IPV as far as possible.

The US National Institutes of Mental Health Committee on Family Violence has proposed a broader description of IPV as 'acts that are physically and emotionally harmful or that carry the potential to cause physical harm ... [and] may also include sexual coercion or assaults, physical intimidation, threats to kill or harm, restraint of normal activities or freedom, and denial of access to resources'. ${ }^{9}$ This implies that while a dysfunctional family can lead to IPV, IPV can also be a cause of family dysfunction. ${ }^{10}$ The prevalence of IPV among women is alarming, as up to $52 \%$ face violence in their lifetime in the USA. ${ }^{11}$ Even pregnant women are not spared. In fact it has been suggested that violence during pregnancy may be a more common problem than conditions for which pregnant women are routinely screened..$^{12}$ The prevalence in Africa is said to be the highest globally. ${ }^{13}$ Bailey et al. ${ }^{14}$ gave a prevalence of up to $81 \%$ in their study among pregnant women. Thus screening for IPV in all women is essential for early detection and prompt treatment where possible.

Intervention programmes to curb IPV are not common and often aim to control IPV by separating the victims from the perpetrator. ${ }^{15-17}$ A separation, though it might put an end to abuse, may create another problem. This is because, in a family, separation of partners has several effects on the family unit. Abuse is detrimental to children, but sometimes a separation poses even 
worse problems for the children. ${ }^{18}$ Also, most victims usually face abuse because they are completely dependent on the perpetrator, i.e. the victim is not empowered either financially or otherwise. ${ }^{19}$ In such an instance, a separation might stop the abuse but pushes the victim into another problem of poverty or inability to cope, which in itself is a huge challenge. Therefore separation is hardly ever a solution to abuse as might be expected. Solutions that are aimed at reconciliation or stopping the violence might in the long run be more beneficial.

Problems that result in IPV are most often problems that can be traced and identified. This then implies that possible solutions could be proffered. The problem-solving counselling technique is a structured and systematic approach to resolving problems that are linked to stressful circumstances. ${ }^{20}$ It is said to be particularly suitable for patients whose life problems are adversely affecting or maintaining disorder. It involves the patient identifying and listing problems and then considering what practical ways exist to solve or alleviate the problem. These solutions are tried and then reviewed. ${ }^{20}$ The place of problem-oriented counselling becomes relevant in addressing problems of IPV. The ability to identify causal/risk factors where they exist, trace their origins and proffer possible solutions was explored in this study.

Though some authors advocate long-term counselling sessions, which could be cumbersome and rather discouraging to embark on, short-term intensive one-on-one counselling has also been advocated. ${ }^{17}$ The latter was explored in this study with the aim of avoiding where possible factors that lead to violence. Trying to restore a family unit that has been ravaged by violence was the goal.

\section{Methodology}

Study area: The study was conducted at the antenatal clinic (ANC) of the University of Abuja Teaching Hospital (UATH), Gwagwalada, North Central Nigeria. The ANC attends to an average of 3000 newly pregnant women annually within and around the FCT.

Study population: This consisted of all the pregnant women who attended the ANC of the hospital between September and December 2014.

Study design: The study was a single-blinded randomised controlled trial of pregnant IPV victims.

Inclusion criteria: All pregnant victims of IPV $<34$ weeks who consented to the study were included.

Exclusion criteria: Pregnant women with no intimate partners, e.g. those who were raped by persons they had no relationship with, were excluded from the study.

Sample size determination: The sample size was determined using the formula for proportions with two different arms:

$$
n=\frac{1}{(1-f)}\left[\frac{2 \times\left(z_{\alpha}+z_{\beta}\right)^{2} \times p \times(1-p)}{\left(P_{0}-P_{1}\right)^{2}}\right]
$$

where $n=$ sample size for each arm: $f=$ the proportion of study subjects who are expected to leave the study for reasons other than outcome of the study, i.e. the estimated nonresponse rate $=10 \%$; $\mathrm{Za}$ at $\mathrm{Cl}$ of $95 \%=1.96 ; \mathrm{Z} \beta$, i.e. power of the study at $90 \%=1.28 ; \mathrm{P} 1=$ the proportion of individuals in the exposed group expected to show outcome of interest $=$ assumed to be $50 \%$, i.e. 0.5 .; $\mathrm{Po}=$ the proportions of individuals in the unexposed group expected to show outcome of interest $=11.6 \%:^{13}$

$N=1.11[(2 \times(10.50) \times 0.31 \times(0.69)) / 0.15]=35.7$ approx.36

giving a sample size of 72 , i.e. 36 per arm.

Sampling technique: Systematic sampling was used to recruit 72 IPV victims who were randomised into two arms of 36 each by simple balloting.

Study protocol: An interviewer-assisted survey of the consenting women for IPV was done by the researcher using the Abuse Assessment Scale (AAS) in a private and confidential manner. A total of 72 IPV victims were recruited. The AAS questionnaire is a validated screening tool with five items and assesses frequency and perpetrator of physical, sexual and emotional abuse by anyone. When any question on the screen was answered affirmatively, the AAS was considered positive for abuse. ${ }^{21}$ The sociodemographic data of the eligible 72 women were collected. The victims were then allocated into a control and intervention arm by simple balloting of 36 per arm. A research assistant, who did not know which arm the victims belonged to, assessed their family function at the beginning of the study. This was repeated post intervention. The family function was assessed using the SCORE- $15 .^{22}$ The SCORE-15 (systemic clinical outcome and routine evaluation; http://www.aft. org.uk/view/score.html?tzcheck=1) is well validated as a measure of family functioning. It meets the Child Outcomes Research Consortium (CORC) requirements of taking less than 10 minutes to complete and being free for use. It is listed by CORC as an additional measure, being piloted specifically for use with family therapy. The 15 items assess three dimensions of family function; five assess family strengths, family difficulty and communication.

The intervention arm then went through three counselling sessions at two-weekly intervals, which were made to coincide with their routine visits. Counselling was done using the SOS-DoC frame work (S-offer support and assess safety; O-discuss options; S-validate patient's strengths; Do-document observations, assessment, and plans; C-offer continuity). This frame work was suggested by Ambuel et al. ${ }^{23}$ for interventions in IPV. It combines two therapeutic counselling techniques, ${ }^{20}$ i.e. nondirective counselling, which aims at encouraging the client to discuss her/his problems with the counsellor who, through listening, affirms the patient's worth and allows her/him to take time to express their thoughts; and problem-solving therapy, which involves systematically teaching generic skills in active problem solving to reduce stress and enhance self-efficacy. The framework was individualized for each victim and depending on what was reported as the likely cause of the IPV suggestions were made to resolve such problems. For instance, if a woman reported late meal preparation as cause of violence in her house, a cooking plan was suggested to improve on the previous regime, she experimented with it and at the next counselling encounter it was re-evaluated, with challenges identified and adjusted. The family functions of both the intervention and control group were reassessed at the end, approximately six weeks from the first assessment.

Data analysis: The data were analysed using SPSS version 20 software (IBM Corp, Armonk, NY, USA). Categorical variables were expressed as proportions and percentages while continuous variables were summarised as means \pm standard deviation. 
Chi-square was used to compare the categorical variables while a t-test was used to compare the means between the two groups and changes pre- and post-intervention.

\section{Results}

The majority of the women $(86.1 \%)$ were between 20 and 34 years of age. Approximately $95 \%$ had some form of education and $95.4 \%$ were married in a monogamous family setting. There was no statistically significant difference between the general characteristics of the study participants in the two arms, hence they were comparable (Table 1).

Table 2 is a summary of the family functions between the two study groups at the beginning of the study (pre- intervention). All the dimensions of the SCORE in both arms showed no statistically significant difference as $p$-values were FS 0.164 , FD 0.838 and FC 0.806 , and the total SCORE-15 was 0.443 (Table 3).

In the control group, the mean family communication score changed from 3.23 at baseline to 2.80 at the end of the study with a $p$-value of 0.24 , which was not statistically significant. The family support score also changed from 2.71 to 2.66 , with a $p$-value of 0.77 , which was not statistically significant. The family difficulty score was 2.72 at the beginning and 2.52 at the end of the study. The $p$-value was 0.212 , which was also not statistically significant. The total SCORE-15 dropped from 2.48 at initial assessment to 2.29 at the final assessment. The $p$-value of 0.116 was also not statistically significant.

Table 4 gives the different dimensions of the SCORE-15. In the intervention arm, the mean family communication score at initial assessment improved from 3.58 to 2.87. This change gave a $p$-value of 0.0001 , which was statistically significant. The family support score was 3.26 pre-counselling and became 2.33 post-counselling. The $p$-value was 0.0001 and was statistically significant. The family difficulty score also changed from 3.41 to 2.48 , which was statistically significant with a $p$-value of 0.0001 . The total SCORE-15 dropped from 2.92 pre-counselling to 2.16 post-counselling. The $p$-value of 0.0001 was also statistically significant.

\section{Discussion}

Intimate partner violence still remains a global challenge and a public health problem. ${ }^{12}$ Yet evidence for intervention that could curb this menace is limited. ${ }^{24}$ This study set out to identify the effect of counselling as an intervention strategy on the family function of pregnant IPV victims. The findings are discussed below.

The sociodemographic characteristics of both groups were similar as statistical testing showed no significant difference between the two groups.

The study showed that the majority of the victims $(86.1 \%)$ were between 20 and 34 years with a mean age of $29.8 \pm 5.6$ years. Women above 35 years accounted for only $13 \%$. This showed an inverse relationship between age and IPV. These findings support work by previous investigators who have reported that IPV occurs more in younger women, commonly aged between 26 and 30, and that the risk decreases with age. ${ }^{25}$ This could be due to the fact that younger women are more impulsive in their attitude and also might not be mature enough to handle relationship conflicts. It could also be attributed to absence of economic empowerment, which is commoner in younger than older women.

Table 1: Sociodemographic characteristics of respondents

\begin{tabular}{|c|c|c|c|c|c|}
\hline \multirow[b]{2}{*}{ Variables } & \multicolumn{3}{|c|}{ Study group } & \multirow[b]{2}{*}{ Chi-square } & \multirow[b]{2}{*}{$p$-value } \\
\hline & $\begin{array}{c}\text { Total } \\
\text { freq. (\%) }\end{array}$ & $\begin{array}{c}\text { Control } \\
(n=36) \\
\text { Freq. }(\%)\end{array}$ & $\begin{array}{l}\text { Intervention } \\
(n=36) \\
\text { Freq. }(\%)\end{array}$ & & \\
\hline \multicolumn{6}{|l|}{ Age group (years): } \\
\hline $20-34$ & $62(86.1)$ & $28(77.8)$ & $34(94.4)$ & 4.123 & 0.085 \\
\hline$\geq 35$ & 10 (139) & $8(22.2)$ & $2(5.6)$ & & \\
\hline No formal education & $3(4.2)$ & $3(8.3)$ & $0(0)$ & 6.483 & 0.070 \\
\hline Primary & $8(11.1)$ & $4(11.1)$ & $4(11.1)$ & & \\
\hline Secondary & $18(25.0)$ & $12(33.3)$ & $6(16.7)$ & & \\
\hline Tertiary & $43(59.7)$ & $17(47.2)$ & $26(72.2)$ & & \\
\hline \multicolumn{6}{|l|}{ Marital status: } \\
\hline Single & $2(2.8)$ & $2(5.6)$ & $0(0.0)$ & 2.577 & 0.493 \\
\hline Others & $1(1.4)$ & $0(0.0)$ & $1(2.8)$ & & \\
\hline \multicolumn{6}{|l|}{ Marriage type: } \\
\hline Monogamous & $65(90.3)$ & $33(91.7)$ & $32(88.9)$ & 0.158 & 1.000 \\
\hline Polygamous & $7(9.7)$ & $3(8.3)$ & $4(11.1)$ & & \\
\hline \multicolumn{6}{|l|}{ Religion: } \\
\hline Christianity & $58(80.6)$ & $30(83.3)$ & $28(77.8)$ & 0.355 & 0.767 \\
\hline Islam & $14(19.4)$ & $6(16.7)$ & $8(22.2)$ & & \\
\hline \multicolumn{6}{|l|}{ Occupation: } \\
\hline Unskilled & $41(56.9)$ & $22(61.1)$ & $19(52.8)$ & 7.806 & 0.109 \\
\hline Semi-skilled & $16(22.2)$ & $11(30.6)$ & $5(13.9)$ & & \\
\hline Skilled & $15(20.8)$ & $3(8.3)$ & $12(33.3)$ & & \\
\hline
\end{tabular}


Table 2: Baseline mean family function scores of participants across study groups

\begin{tabular}{lcccc}
\hline $\begin{array}{l}\text { Dimension } \\
\text { of family } \\
\text { function }\end{array}$ & $\begin{array}{c}\text { Control } \\
(\boldsymbol{n}=36) \\
\text { Mean (SD) }\end{array}$ & $\begin{array}{c}\text { Intervention } \\
(\boldsymbol{n}=36) \\
\text { Mean (SD) }\end{array}$ & t-test & $\boldsymbol{p}$-value \\
\hline FS & $2.64(0.68)$ & $3.26(1.07)$ & 1.405 & 0.164 \\
FD & $2.64(0.67)$ & $3.41(1.00)$ & 0.206 & 0.838 \\
FC & $3.19(0.85)$ & $3.58(0.86)$ & 0.247 & 0.806 \\
SCORE-15 & $2.42(0.66)$ & $2.92(0.93)$ & 0.772 & 0.443 \\
\hline
\end{tabular}

Key: $F F=$ family function, $F C=$ family communication, $F S=$ family strength, $F D=$ family difficulty, SCORE-15 = Systemic Clinical Outcome and Routine Evaluation 15.

Table 3: Comparison of baseline and post-intervention mean family function scores of control group

\begin{tabular}{lcccc}
\hline $\begin{array}{l}\text { Dimension of } \\
\text { family } \\
\text { function }\end{array}$ & $\begin{array}{c}\text { Baseline } \\
\text { FF }\end{array}$ & $\begin{array}{c}\text { End of } \\
\text { study FF }\end{array}$ & $\begin{array}{c}\text { Paired } \\
\text { t-test }\end{array}$ & $\begin{array}{c}\boldsymbol{p} \text { - } \\
\text { value }\end{array}$ \\
\hline FC & $3.23(0.87)$ & $2.80(0.97)$ & 2.356 & 0.24 \\
\hline FS & $2.71(0.75)$ & $2.66(0.98)$ & 0.283 & 0.779 \\
FD & $2.72(0.78)$ & $2.52(0.78)$ & 1.271 & 0.212 \\
\hline SCORE-15 & $2.48(0.73)$ & $2.29(0.82)$ & 1.614 & 0.116 \\
\hline
\end{tabular}

The study showed that over $90 \%$ of the victims had undergone formal education and a significant proportion had up to a tertiary level of education. This showed that educational status is not protective against IPV. This, however, has been argued differently by certain investigators. Efetie et $a .^{26}$ also found high proportion of educated people in their study. Some other investigators have argued that education might be protective. $^{27}$

As high as $62.5 \%$ were low-income earners, thus placing the majority of the victims in a low economic class. This agrees with several other studies, which have postulated that women's economic vulnerability further facilitates partner abuse. ${ }^{27,28}$ At an individual and household level, economic development and poverty reduction may have protective impacts on IPV. ${ }^{29}$ However, context-specific factors influence whether financial autonomy is protective or associated with increased risk, as a perpetrator could view this as a threat to his dominance. ${ }^{29}$

The majority of the women (95.8\%) were married, $2.8 \%$ were single and $1.4 \%$ were separated from their husband. This agrees with some other authors who have said that married women were more likely to be with their spouses and hence have an increased chance of suffering violence. ${ }^{30}$ However, another study in Japan had a contrary view stating that IPV occurred equally or even occurs more among single relationships than among those who are married. ${ }^{31}$

Table 4: Dimension of family function (SCORE-15) of study participants who received counselling

\begin{tabular}{lcccc}
\hline $\begin{array}{l}\text { Dimension of } \\
\text { family } \\
\text { function }\end{array}$ & $\begin{array}{c}\text { Baseline } \\
\text { FF }\end{array}$ & $\begin{array}{c}\text { End of } \\
\text { study FF }\end{array}$ & $\begin{array}{c}\text { Paired } \\
\text { t-test }\end{array}$ & $\begin{array}{c}\boldsymbol{p} \text { - } \\
\text { value }\end{array}$ \\
\hline FC & $3.58(0.86)$ & $2.87(0.93)$ & 5.002 & 0.0001 \\
\hline FS & $3.26(1.07)$ & $2.33(0.91)$ & 5.346 & 0.0001 \\
\hline FD & $3.41(1.01)$ & $2.48(0.93)$ & 4.082 & 0.0001 \\
\hline SCORE-15 & $2.92(0.92)$ & $2.16(0.63)$ & 5.068 & 0.0001 \\
\hline
\end{tabular}

Most of the victims (80.6\%) were Christians while $19.4 \%$ were Muslims. There were no traditional worshippers. Though this could be a chance finding it could be attributed to the fact that more Christian women in the area of study were enlightened and hence would more likely seek antenatal care. However, some authors have postulated that Christian beliefs concerning the sanctity of marriage and partner and community pressure to present as model Christians serve to shame and silence battered women, hence Christian women might be more at risk of IPV. ${ }^{32}$ Some other authors found a Muslim predominance in their study. ${ }^{33}$

IPV has been shown to be associated with family dysfunction. ${ }^{5,10}$ In the present study, family dysfunction was established in approximately $85 \%$ of the victims prior to intervention. In the control arm, family dysfunction was reported in about $77.8 \%$ of the victims at the beginning of the study with $2.8 \%$ having a severely dysfunctional family. At the end of the study, $72.2 \%$ of the victims still had dysfunctional families while the severely dysfunctional category increased to $5.6 \%$, implying no change in family function. This corroborates the findings of other researchers who pointed out that IPV negatively impacts on family function. $^{34}$ In the intervention arm, $86.2 \%$ of participants had dysfunctional family pre-counselling, of which $5.6 \%$ were severely dysfunctional. However, at the end of the intervention (which was one to two hours of two-weekly counselling sessions for six weeks), the number of victims had reduced to $61.1 \%$ and no one had a severely dysfunctional family. This change was found to be statistically significant, corroborating the work of Heru, ${ }^{16}$ who concluded at the end of his study that IPV would plateau or even worsen without any form of intervention.

This study demonstrated the effect of short-term counselling on the family function of IPV victims. At the end of the study, the intervention group who received three sessions of fortnightly individualised problem-specific counselling were found to have a statistically significant improvement in their total family function and the dimensions (FC, FD, and FS) of family function. In the control arm none of the dimensions of family functioning (FC, FD, FS) demonstrated any statistically significant change at the end of the study.

Furthermore, a comparison of the control and intervention groups showed improvement in the dimensions of the SCORE15. This improvement was found to be statistically significant across all the dimensions of family function. Some other investigators have also noted an improvement in the impact of IPV using varying interventions. ${ }^{35,36}$ Bailey $^{14}$ in her review pointed out that there was evidence suggesting that brief advocacy intervention increases the use of safety behaviours in both the short and long term, even for women who remain with the perpetrator. However, other authors have suggested that insufficient evidence exists to show whether less intensive interventions in healthcare settings for women who still live with the perpetrators of violence are effective. ${ }^{14,17}$

\section{Conclusion}

The burden of IPV in pregnancy still remains enormous with a significant impact on the family, which is the smallest functional unit of the community. However, this study showed that intensive short-term counselling could help forestall this ugly menace. This was proved by the significant improvement in the mean family function scores in the intervention arm compared with the controls. 


\section{Recommendations}

In view of these findings the following is being recommended concerning IPV in pregnancy:

1. Screening for IPV should be incorporated into the consultation plan for every pregnant woman at the antenatal clinic.

2. Physicians should be equipped with simple short-term counselling protocols that could help to abate some of the complications of IPV.

3. This study was rather short term, thus a longer term evaluation of this intervention is needed to examine user outcomes and determine its effectiveness, and also to assess the effects of additional time on implementation.

4. Further research could be done in the general population or among men.

Ethical considerations - Ethical approval for the study was obtained from the Ethics and Research Committee of the UATH, Gwagwalada. All the participants were provided with a subject information sheet containing the details of the research and their participation, and written informed consent was obtained.

Disclosure statement - No potential conflict of interest was reported by the authors.

\section{References}

1. Kurst-Swanger K, Petcosky JL. Violence in the home: multidisciplinary perspectives. Oxford, England: Oxford University Press; 2003;1-336.

2. Alaniz R, De Los Santos E. Domestic violence: it can happen to professional women including educators. Int J Edu Soc Sci. 2015;2 (12):1-10.

3. Koenen KC, Moffitt TE, Caspi A, Taylor A, Purcell S. Domestic violence is associated with environmental suppression of $\mathrm{IQ}$ in young children. Dev. Psychopathol.. 2003;15(2):297-311. https://doi.org/10.1017/ S0954579403000166

4. Huth-Bocks AC, Hughes HM. Parenting stress, parenting behavior, and children's adjustment in families experiencing intimate partner violence. J Fam Violence. 2008;23(4):243-51. https://doi.org/10. 1007/s10896-007-9148-1

5. Kalpana M. Dysfunctional family: what are its signs and how to overcome its effects. Available from: http://www.momjunction.com/ articles/harsh-reasons-of-dysfunctional-family-relationships_004078 $60 / \# g r e f$

6. Max W, Rice DP, Finkelstein E, Bardwell RA, Leadbetter S. The economic toll of intimate partner violence against women in the United States. Violence Vict. 2004;19(3):259-272. https://doi.org/10.1891/ vivi.19.3.259.65767

7. Nugent, Pam MS. Dysfunctional family. In PsychologyDictionary.org, 2013 April 7. Available from: https://psychologydictionary.org/ dysfunctional-family/ (accessed May 1, 2018).

8. Aymer SR. Beyond power and control: clinical interventions with men engaged in partner abuse. Clin Soc Work J. 2008;36(4):323-32. https://doi.org/10.1007/s10615-008-0167-z

9. Crowell NA, Burgess AW, editors. National research council. understanding violence against women. Washington, DC: National Academy Press; 1996. 9-17.

10. Ambriz-Mora Ml, Zonana-Nacach A, Anzaldo-Campos MC. Intimate partner violence and family dysfunction among Mexican women seen a primary care unit. Semergen. 2015;41(5):241-6. https://doi. org/10.1016/j.semerg.2014.07.004

11. Bachman R, Saltzman LE. Violence against women: estimates from the redesigned survey. Washington, DC: Bureau of Justice Statistics, US Department of Justice; 1995.
12. World Health Organization. Intimate partner violence during pregnancy: Information sheet. 2011 Available from: www.who.int/ reproductivehealth

13. Gyuse AMI, Ushie AP. Pattern of domestic violence among pregnant women in Jos, Nigeria. S Afr Fam Pract. 2009;51(4).

14. Bailey, B.A., Daugherty, R.A. Intimate partner violence during pregnancy: incidence and associated health behaviors in a rural population. Matern Child Health J. 2007;11:495-503. https://doi.org/10. 1007/s10995-007-0191-6

15. Silverman JG, Decker MR, Reed E, Raj A. Intimate partner violence victimization prior to and during pregnancy among women residing in 26 US states: associations with maternal and neonatal health. Am J Obstet Gynecol. 2006;195(1):140-8. https://doi.org/10.1016/j.ajog. 2005.12.052

16. Heru AM. Intimate partner violence: treating abuser and abused. Adv Psychiatr. Treat. 2007;13(5):376-83. https://doi.org/10.1192/apt.bp. 107.003749

17. Ramsay J, Carter Y, Davidson L, Dunne D, Eldridge S, Hegarty K, et al. Advocacy interventions to reduce or eliminate violence and promote the physical and psychosocial wellbeing of women who experience intimate partner abuse. Cochrane Database Syst Rev. 2009;8(3):13-14.

18. Capaldi DM, Knoble NB, Shortt JW, Kim H. A systematic review of risk factors for intimate partner violence. Partner Abuse. 2012;3(2):23180. https://doi.org/10.1891/1946-6560.3.2.231

19. Hegarty K, O'Doherty L, Taft A, Chondros P, Brown S, Valpied J, et al. Screening and counselling in the primary care setting for women who have experienced intimate partner violence (WEAVE): a cluster randomised controlled trial. Lancet. 2013;382(9888):249-58. https:// doi.org/10.1016/S0140-6736(13)60052-5

20. Colin T. Counselling in primary care. Patient. 2014;2013(26). Available online at https://patient.info/doctor/counselling-in-primary-care

21. Rabin RF, Jennings JM, Campbell JC, Bair-Merritt MH. Intimate partner violence screening tools: a systematic review. Am J Prev Med. 2009;36(5):439-45. https://doi.org/10.1016/j.amepre.2009.01.024

22. Stratton P, Bland J, Janes E, Lask J. Developing an indicator of family function and a practicable outcome measure for systemic family and couple therapy: the SCORE. J Fam Ther. 2010;32(3):232-58. https:// doi.org/10.1111/j.1467-6427.2010.00507.x

23. Ambuel B, Hamberger L, Lahti J. The family peace project: a model for training health care professionals to identify, treat and prevent partner violence. J Aggress Maltreat Trauma. 1998;1(2):72-3. https://doi.org/10.1300/J146v01n02_04

24. Wathen $\mathrm{CN}$, Macmillan HL. Interventions for violence against women: scientific review. JAMA. 2003: 289(5):589-600. https://doi.org/10. 1001/jama.289.5.589

25. Rivara FP, Anderson ML, Fishman P, Reid RJ, Bonomi AE, Carrell D, et al. Age, period, and cohort effects on intimate partner violence. Violence Vict. 2009;24(5):627-38. https://doi.org/10.1891/0886-6708. 24.5.627

26. Efetie E, Salami H. Domestic violence on pregnant women in Abuja, Nigeria. J Obstet Gynaecol. 2007;27(4):379-82. https://doi.org/10 1080/01443610701327552

27. Claudia G-M, Alessandra G, Wendy K. Understanding and Addressing Violence against Women. Available from: http://www.who.int/ reproductivehealth/publications/violence/en/index.html 2012.

28. Shamu S, Abrahams N, Temmerman M, Shefer T, Zarowsky C. That pregnancy can bring noise into the family: exploring intimate partner sexual violence during pregnancy in the context of HIV in Zimbabwe. PloS one. 2012;7(8):43-8. https://doi.org/10.1371/ journal.pone.0043148

29. Vyas S, Watts C. How does economic empowerment affect women's risk of intimate partner violence in low and middle income countries? A systematic review of published evidence. J Int Dev. 2009;21(5):577602. https://doi.org/10.1002/jid.1500

30. Reed E, Raj A, Miller E, Silverman JG. Losing the gender in genderbased violence: the missteps of research on dating and intimate partner violence. Violence Against Wom. 2010;16(3):348-54. https:// doi.org/10.1177/1077801209361127

31. Yoshihama M, Horrocks J, Kamano S. Experiences of intimate partner violence and related injuries among women in Yokohama, Japan. Am. J Public Health. 2007;97(2):232-4. https://doi.org/10.2105/AJPH. 2005.078113 
32. Knickmeyer N, Levitt $\mathrm{H}$, Horne SG. Putting on Sunday best: the silencing of battered women within christian faith communities. Fem Psychol. 2010;20(1):94-113. https://doi.org/10.1177/0959353509347470

33. Fatusi AO, Alatise OI. Intimate partners' violence in lle-Ife, Nigeria: women's experiences and men's perspectives. Gender Behaviour. 2006;4(2): 764-81.

34. Archna N, Gina A, Lisa M. Intimate partner violence: patients' experiences and perceptions in family practice. Fam Prac. 2012;29(5):593600. https://doi.org/10.1093/fampra/cms008
35. Suårez-Orozco C, Todorova IL, Louie J. Making up for lost time: the experience of separation and reunification among immigrant families. Fam Process. 2002;41(4):625-43. https://doi.org/10.1111/j. 1545-5300.2002.00625.x

36. Rees K, Zweigenthal V, Joyner K. Implementing intimate partner violence care in a rural sub-district of South Africa: a qualitative evaluation. Global Health Act. 2014;7:1654-988.

Received: 19-06-2018 Accepted: 29-08-2018 